\title{
LUANDA, CIDADE-MUNDO, OU DA ESTÉTICA DO DESENVOLVIMENTO DESIGUAL EM OS TRANSPARENTES, DE ONDJAKI
}

\section{LUANDA, WORLD-CITY, OR THE AESTHETICS OF UNEQUAL DEVELOPMENT IN OS TRANSPARENTES, BY ONDJAKI}

Adriana Cristina Aguiar Rodrigues 
RESUMO: A entrada de Angola na economia neoliberal e o fim da guerra civil deram a Luanda o aspecto de um canteiro de obras que visava conferir a ela o status de cidade global. Todavia, as mudanças econômicas advindas das relações (assimétricas) com o capital internacional não foram capazes de obliterar a permanência de desigualdades e da lógica espacial de exclusão incrustrada na urbe. Tomando esse contexto e as concepções de literatura-mundo definidas por membros do Warwick Research Collective (2015), o artigo analisa as contradições do sistema-mundo capitalista no romance Os transparentes (2013), de Ondjaki, compreendido aqui como expressão cultural da lógica contraditória da modernidade.

Palavras-chave: literatura-mundo, Luanda, Os transparentes, Ondjaki. 
Abstract: Angola's entry into the neoliberal economy and the end of the civil war gave Luanda the appearance of a building site aiming the status of a global city. However, the economic changes resulting from (asymmetric) relations with international capital were not able to remove the existing inequalities and the spatial logic of exclusion embedded in the city. Taking this context and the conceptions of World-Literature defined by members of the Warwick Research Collective (2015), the article analyzes the contradictions of the capitalist world-system in Ondjaki's novel Os transparentes (2013), understood here as a cultural expression of the contradictory logic of modernity.

Keywords: world-literature, Luanda, Os transparentes, Ondjaki. 
[...] era um prédio, talvez o mundo (ONDJAKI, 2013, p. 69).

Em 2015, o coletivo de pesquisadores do departamento de Estudos Literários Ingleses e Comparados da Universidade de Warwick, denominado WReC (Warwick Research Collective), publicava, pela Liverpool University Press, o livro intitulado Combined and uneven development towards: a new theory of world-literature, resultado do desafio, adotado pelos membros do grupo, de pensar e ressituar o campo dos estudos literários no novo milênio e as implicações culturais e literárias das teorias sistêmica e do desenvolvimento combinado e desigual para propor uma abordagem da produção literária mundial. No primeiro capítulo do livro - "World-literature in the context of combined and uneven development" -, o grupo de pesquisadores parte da crise da literatura, entendida tanto como objeto da cultura subordinada às leis de mercado quanto campo de estudos cujos métodos institucionalizados e consolidados necessitam - como apontam diferentes estudiosos, dentre eles Raymond Williams, em 1981, e Spivak, em $2003^{1}$ - ser repensados, reorientados, reinventados.

É nesse contexto que o debate sobre as noções de "literatura mundial" é introduzido no livro. Se, ini-

${ }^{1}$ Conferir: SPIVAK, Gayatri Chakravorty. Death of a discipline. New York: Columbia University Press, 2003. 
cialmente, essa expressão situava-se no arco das discussões estabelecidas no campo dos estudos pós-coloniais e da contestação (após os debates multiculturais) de categorias como "eurocentrismo" e "nação" que assinalavam os estudos de literatura comparada, atualmente o termo "literatura mundial" passou a engendrar uma noção pan-disciplinar, estendendo-se para além dessas duas áreas a que inicialmente era vinculado (WReC, 2015). Dissentindo de concepções, como as de David Damrosch (2003), que entendem a literatura mundial relativamente à circulação, às obras primas ou aos grandes autores, aos modos de produção e recepção da literatura, o WReC situa as produções literárias como parte integrante de um único sistema literário em que o capitalismo é o substrato e define literatura mundial como a literatura do sistema-mundo capitalista moderno (2015, p. 7), optando, assim, por reinscrever a categoria de pesquisa na forma "literatura-mundo", com hífen.

Tal proposição deriva de desenvolvimentos teóricos advindos das ciências sociais, dentre eles a teoria sistêmica articulada por Immanuell Wallerstein (2005), a partir da qual a unidade de análise do cenário econômico, político e social que configura as relações mundiais deixa de ser o Estado-nação e passa a ser o sistema-mundo capitalista, interestatal. Conforme o sociólogo argumenta, o sistema moderno mun- 
dial (capitalista) é constituído por uma economia em incessante expansão, a partir de um mundo articulado por um complexo sistema de trocas econômicas (desiguais), cuja divisão internacional do trabalho é baseada na tensão centro, semiperiferia e periferia. Esse sistema único tem como característica a heterogeneidade cultural, política e econômica, não atribuída ao atraso de uma região em relação a outra, mas à própria natureza do sistema-mundo. 0 que o $\mathrm{WReC}$ faz, portanto, é se apropriar da teoria sistêmica para pensar a literatura mundial.

Esta concepção reflete ainda argumentos desenvolvidos por outro sociólogo, Fredric Jameson, especificamente no que se refere a uma "modernidade singular", que evoca, por sua vez, a teoria do desenvolvimento combinado e desigual - isto é, formas e relações capitalistas existindo ao lado de formas arcaicas de vida econômica e de relações sociais e de classe pré-existentes e desigual -, cuja genealogia situa-se em teóricos como Marx, Engels, Lênin e Trotsky. Jameson revisita essa teoria, associando-a à noção de modernidade para afirmar que essa só pode ser conceitualizada adequadamente por referência ao capitalismo mundial, sendo a modernidade, como o próprio sistema-mundo, um fenômeno singular (WReC, 2015, p. 11). Não se trata, portanto, de uma categoria cronológica ou geográfica, mas de 
uma situação geral, globalmente dispersa, maneira pela qual relações sociais capitalistas mundiais são vividas simultaneamente, de forma singular, porém internamente heterogênea e desigual.

Já no campo dos estudos literários, a hipótese do coletivo de pesquisa de Warwick dialoga, em parte, com a tese de Pascale Casanova (2002), no que tange à existência de um espaço literário internacional ou de uma "república mundial das letras" estruturada por assimetrias de circulação e troca; e de Franco Moretti (2000), no que toca à sistematicidade heteronômica e desigual da produção literária mundial. Em síntese, a noção desenvolvida pelo WReC (2015), implica compreender: um sistema mundial único, porém radicalmente desigual; uma modernidade singular, combinada e desigual; e uma literatura que, de múltiplas maneiras, registra essa desigualdade combinada, tanto em sua forma quanto em seu conteúdo.

Saltando do capítulo que abre o livro para o que o encerra, intitulado "Ivan Vladislavic: traversing the uneven city", é possível acompanhar de forma mais detida as implicações do conceito de literatura-mundo proposto pelo WReC na análise (paradigmática, e não exemplar, como os próprios autores destacam) que é feita de coletâneas de contos de Vladislavic, gênero literário declaradamente preferido pelo autor como a forma representativa apropriada 
à realidade extrema da cidade de Joanesburgo. Como o título do capítulo sugere, os autores analisam o que denominam "estética do desenvolvimento desigual" ou "expressões culturais da lógica contraditória da modernidade capitalista globalizada" (WReC, p. 144) na contística desse escritor sul-africano, apontando como preocupações formais e temáticas de sua obra são expressões estéticas das contradições e paradoxos da modernidade desigual incorporada na vida cotidiana da África do Sul pós-apartheid (WReC, 2015, p. 146).

$\mathrm{Na}$ forma como são entendidos pelo WReC, os contos de Vladislavic, ao registrarem a profunda e perturbadora incompatibilidade entre o tecido construído das cidades sul-africanas e a política aspiracional da "nova" África do Sul, mesclam elementos do formalismo real com outros do que a crítica convencionou chamar "realismo mágico africano" para compor a aura de um espaço (Joanesburgo) e tempo histórico particular (a era do capitalismo tardio ou milenar) que permite ao leitor testemunhar e refletir sobre uma estrutura global formada ao longo da duração do desdobramento da modernidade. Dito de outra forma, a cidade de Joanesburgo é, portanto, chave para entender a compulsão histórica sob a qual modos culturais operam em condições de desenvolvimento desigual (WReC, 2015, p. 145). 
A questão colocada pelos membros do WReC é se esta cidade pós-apartheid pode ser descolonizada, liberada das divisões do trabalho e da vida que sua forma material construída, seu designe e layout, suas estradas e redes de comunicação continuam a codificar e institucionalizar. Na esteira de James Graham, os pesquisadores assentem que o retrato da Joanesburgo criado por Vladislavic gira em torno da contradição, isto é, o dinamismo e a multiplicidade do espaço da cidade são bastante reais, mas sua potencialidade social é comprometida pelos limites impostos pelo peso morto do passado: ainda que as pessoas façam uso da antiga cidade, a memória dela, com suas divisões e desigualdades codificadas dentro de seu próprio tecido, continua ecoando no presente (WReC, 2015, p. 146).

Tanto o primeiro capítulo quanto o último do livro assinado pelo WReC situam as questões que buscamos analisar neste texto, isto é, os modos como o romance Os transparentes (2013), de Ondjaki, enquanto forma literária e manifestação cultural, apropria-se de condicionamentos político-econômicos decorrentes da inserção de Angola na economia neoliberal e da transição de sua capital, Luanda, para uma forma de metrópole - o que Achille Mbembe e Sarah Nuttall (2008) denominam "afrópolis". Considerando que a forma literária romanesca é, conforme defendem os 
membros do coletivo, o gênero em que o desenvolvimento combinado e desigual se manifesta mais nitidamente devido à sua associação fundamental com a ascensão do capitalismo e seu status nas sociedades periféricas e semiperiféricas, além de sua plasticidade e hibridismo que permitem incorporar, dentre outros aspectos, diferentes formas culturais não literárias e arcaicas (WReC, 2015, p. 16), nosso objetivo aqui é, de modo análogo ao procedimento adotado pelo coletivo de Warwick, analisar a narrativa em tela, interpretando-a na chave estética do desenvolvimento desigual, da literatura-mundo.

Lançado em Portugal em 2012, pela Editora Caminho, e no Brasil, em 2013, pela editora Companhia das Letras, o romance é composto por oito partes (em que a última é a continuação da primeira), seccionadas por páginas escuras que abrem cada uma delas com narrativas orais curtas. Essa estrutura sugere semelhança com o conteúdo da narrativa, cujo enredo decorre, principalmente, dos acontecimentos envolvendo as personagens de um edifício de 7 andares, sobre o qual é dito: "era um prédio, talvez o mundo” (ONDJAKI, 2013, p. 69). É a partir desse espaço ficcional localizado no coração de Maianga, historicamente um dos primeiros bairros de Luanda, que o leitor pode acompanhar, então, condicionamentos econômicos, políticos e sociais de um país da África 
austral inserido na lógica contraditória da modernidade capitalista globalizada. 0 livro se inicia com a descrição-narração de duas personagens, um Cego e um menino VendedorDeConchas que tenta atender ao desejo do mais-velho de descobrir a cor do fogo, que seus olhos não podem ver, mas sua pele sente, enquanto ambos buscam escapar a uma grande explosão. Aos poucos o leitor nota que essa é a ameaça que paira sobre Angola da especulação petrolífera e da Luanda imagem-reservatório do óleo negro, canteiro de obras cercado por tapumes e andaimes e minada por crateras escavadas por uma Comissão Instaladora do Petróleo Encontrável em Luanda (CIPEL), com a colaboração dos Estados Unidos, da Rússia, França, Índia e do Brasil (ONDJAKI, 2013, p. 161). É esse tom apocalíptico que envolve o conteúdo da narrativa até o seu final, quando o capítulo inicial é retomado e o leitor pode, então, acompanhar a ruína dessa cidade do século XXI.

Ao discorrer sobre a inserção da África subsaariana no sistema-mundo capitalista, Monié; Amorim; e Gayer (2007) analisam que durante o secular processo de unificação desse sistema as relações entre essa parte do continente e o resto do planeta foram caracterizadas pela sua crescente participação nas redes econômicas, comerciais, financeiras e político-diplomáticas que moldaram uma inserção de caráter 
periférico na divisão internacional do trabalho. Não obstante as tendências que caracterizam as últimas décadas e as transformações que ilustram a complexidade crescente das relações entre o continente e o resto do mundo - como diversificação dos fluxos comerciais, constituição de novas redes político-econômicas, participação dos representantes das culturas africanas na indústria cultural global -, a evolução dessas relações na longa duração evidencia a perpetuação de sistemas de exploração e opressão que especializaram esta região periférica, caracterizada pela importação de bens de maior valor agregado e pela oferta de matéria-prima - o que representa até hoje entre $75 \%$ e $80 \%$ das receitas de exportação (MONIÉ; AMORIM; GAYER, 2007).

Angola, inserida nesse contexto geoeconômico, apresenta características semelhantes às descritas por Monié; Amorim; e Gayer (2007). Da independência política, em 1975, até 1988 o Estado procurou aproximar-se do bloco socialista, apresentando uma economia fortemente afetada pelos entraves oriundos do colonialismo, da Guerra Fria e da guerra civil. A partir de 1990, pressionado por desdobramentos de eventos internacionais e locais, o governo do MPLA (Movimento Popular Pela Libertação de Angola) dá uma guinada, inserindo-se na economia neoliberal (sob a tutela do Banco Mundial e do FMI), mas 
permanecendo, ainda, no modelo primário-exportador, reforçado, sobretudo, pelas expectativas quanto à sua potencialidade no cenário energético global, para o qual já vinha despontando como importante fornecedor de petróleo desde meados de 1970 (MONIÉ; AMORIM; GAYER, 2017).

As mudanças político-econômicas, juntamente com o fim do conflito civil, em 2002, fizeram com que o PIB do país saltasse de 8.022 milhões de dólares, em 1988, para 11.204, em 2002, e 112.700 milhões de dólares, em 2012². Nesse cenário, o governo lançou, em 2003, um programa nacional de reconstrução, que favoreceu um boom no setor de construção civil, repaginando o cenário urbano de Luanda com arranha-céus de paredes espelhadas, condomínios habitacionais e cidades satélites financiadas, especialmente, por linhas de créditos petrolíferos com a China. Todavia, Claudia Gastrow (2017a) argumenta que as perspectivas materiais, geográficas e populacionais dessa cidade emergente foram moldadas em pactos entre as elites angolanas e o capital internacional que recapitularam as antigas tensões sobre a pertença nacional, fazendo surgir, nas margens urbanas, vastas zonas de realojamento para os despoja-

\footnotetext{
${ }^{2}$ Dados disponíveis em: FILHO, Alcides Goulart; CHIMBULO, Avelino Euclides da Silva. Política econômica de Angola de 1975 a 2012: a trajetória da mudança de modelos. In: Revista de Desenvolvimento Econômico (RDE), ano XVI, n. 29, dez, 2014, Salvador, BA. p. 92-105.
} 
dos pelo redesenvolvimento. Frederic Monié (2012) corrobora o ponto de vista dessa antropóloga sul-africana, ao afirmar que, embora, por um lado, o petróleo seja a matéria prima que coloca a África subsaariana no cenário energético global e a pujança do atual boom petrolífero contribua para a aceleração do crescimento econômico, levanta, por outro lado, sérios questionamentos quanto ao potencial desenvolvimentista e aos impactos da atividade sobre os espaços e as sociedades.

Como produto cultural, o romance de Ondjaki capta essas dissensões entre desenvolvimento econômico e impactos sociais e espaciais. Como obra em que o espaço urbano é tema e cenário, a narrativa assemelha-se a um mapa de Luanda/Angola, concentrado em três núcleos interconectados: o econômico, o político e o social. No primeiro, tematiza-se a mercantilização de tudo e de todos: "Luanda fervia com a sua gente que vendia, que comprava para vender, que se vendia para depois comprar e gente que se vendia sem voltar a conseguir comprar" (ONDJAKI, 2013, p. 67). Situam-se nesse núcleo, as temáticas da exploração a qualquer custo do petróleo, das privatizações, da economia informal, da circulação de produtos importados da Europa, dos Estados Unidos, da China, do Brasil, dos mais diversos lugares do globo - produtos aos quais os mais pobres têm acesso apenas 
parcialmente, ficando com nada ou com restos, como celulares sem crédito que custam a vida de Paizinho. Inclui-se nessa lógica a comercialização internacional de um eclipse (cancelado pelo Presidente da República); a comercialização de uma inflamação nos testículos de Edú (o "mbumbi", tornado espetáculo em programa de TV e especulado como fonte financeira); a comercialização da fé e da espiritualidade capitalizadas e prostituídas na IgrejaDaOvelhinhaSagradada. Tematiza-se, enfim, a mercantilização da cidade - mais um supermercado que atende a desejos globalizados de uma pequena elite do que um lugar de habitação (WReC, 2015).

No núcleo político, o leitor se depara com a sátira de um Estado em que dominam práticas de clientelismo, patrimonialismo, tráfico de influência, corrupção e má gestão dos recursos públicos. Uma cleptocracia, dependente de uma única fonte de receitas e com índices críticos de desenvolvimento humano. São fartas, na narrativa, as ocasiões em que funcionários públicos exigem propina de civis e turistas em aeroportos, nas ruas, no trânsito, em moradias, em presídios, como é o caso dos fiscais DestaVez e DaOutra que extorquem nas situações mais inusitadas e evadem divisas para Portugal. Nesse núcleo, o leitor pode acompanhar ainda o desperdício de recursos públicos, onde Assessor e Ministro gozam de carros 
com ar-condicionado, motoristas particulares, além de consumirem bebidas nacionais (como whisky) e internacionais (como vinho português e água francesa engarrafada). São diversas também as cenas de abuso de poder, em que o Assessor do Ministro expõe DonaCreuza, a secretária, a situações vexatórias, obrigando-a a comprar, com recursos próprios, o gelo para bebidas alcoólicas consumidas durante expediente de trabalho. A ausência do Estado fica ainda mais evidente nas poucas vezes em que se fala do Presidente, cuja presença ocorre como uma espécie de ausência, isto é, apenas uma imagem, via TV, ou uma voz, via rádio. A única vez em que aparece em público é na ocasião em que se comemora a suposta descoberta de petróleo em Luanda, quando sofre um atentado e morre.

O desnível econômico e a ineficácia das políticas e gestão estatais são codificados no tecido social, onde a lógica desigual do sistema-mundo capitalista toma a forma de uma segregação vertical (social) que se manifesta, por sua vez, no espaço construído da cidade. Como afirmamos, a narrativa concentra-se em um prédio de 6 andares e 1 terraço, onde habitam e transitam grupos de sujeitos cuja existência tensiona sobrevivência e resistência em uma cidade que lhes nega o direito à cidadania, ao pertencimento (GASTROW, 2017a; 2017b). No primeiro andar, 
além de uma abertura que serve de passagem e que modula as fronteiras e porosidades entre a realidade interna dos moradores e a realidade externa da cidade, há uma espécie de fonte/lagoa, cujas águas parecem produzir efeitos incomuns nos moradores e nos que circulam pelo prédio. Nesse ponto da narrativa, encontra-se uma referência histórica ao bairro da Maianga, termo originário do quimbundo, "mazanga", no português, "poço". No século XVII foram criadas, nessa região, duas maiangas: a do povo, que abastecia a população, e a do rei, que abastecia os portugueses.

No segundo andar do prédio, residem a quitandeira MariaComForça e seu esposo, o "homme d'affaires", JoãoDevagar. No terceiro, vive o lavador de carros e carregador de água Paizinho, vindo, como outros, do interior de Angola, à procura de sua mãe, de quem se perdeu durante a guerra civil. Apesar de o narrador não esclarecer sobre a conjuntura que levou a população do prédio a ocupá-lo, é possível acompanhar a trajetória dessa personagem que antes

vivera na rua, usara drogas, roubara roupas e comida, e de algum modo a vida se encarregou de lhe organizar as horas e as ocupações, não se lembra bem como aproximou-se do prédio, lá começou a lavar carros e a ganhar a confiança das pessoas, até que foi autorizado 
a pernoitar lá, primeiro nas traseiras do prédio, na companhia de infinitas baratas e outros mosquitos, depois, [...] por deliberação coletiva dos residentes [...] lhe foi atribuído o muito abandonado terceiro andar [...], completamente esvaziado e escuro, de ausentes portas e janelas bem arejadas, o qual aceitou com emoção e agrado, e nessa primeira noite, emocionado por finalmente ter um teto, não conseguiu dormir (ONDJAKI, 2013, p. 240-241).

Aí se pode inferir as condições de moradia na cidade, bem como alguns detalhes do interior do prédio, com suas escadas e portas que dão a lugar algum. Além disso, é possível dimensionar também a relatividade da ideia de morada, de lar: o menino sente-se grato e comove-se por ter deixado as calçadas infestadas de insetos e por passar a "residir" em espaço com estrutura precária.

No andar acima do ocupado por Paizinho, habitam a quitandeira Nelucha e o esposo Edú. No quinto, mora CamaradaMudo, descascador de batatas e cebolas e amante da música (outra vez uma referência histórica ao bairro, conhecido por ser o lar de músicos de destaque em Angola). No sexto piso, convive a família de AvóKunjikise, Odonato, Xilisbaba e Amarelinha. No sétimo, localiza-se o terraço, de onde Odonato, em sua transparência, contempla Luanda da 
atualidade e onde ocorrem sessões de teatro vivo no Cinema GaloCamões, promovidas por JoãoDevagar. A esse prédio e a suas personagens se ligam outros espaços dessa Luanda ficcionalizada, como a PraiaDallha (onde passam as noites o menino, oriundo do Bengo, VendedorDeConchas e o Cego); o prostíbulo da AvóTeta, no musseque BairroOperário, onde se dá a comercialização dos corpos de meninas; o prédio onde se acomodam o filho de Odonato, CienteDoGrã, ZéMesmo e a comunidade rastafári - próximo ao Palácio Presidencial (onde nunca falta energia elétrica tampouco seca a maianga dos novos reis) -; o Bar ArcaDeNoé; o musseque do Carteiro; a Esquadra policial; e o Cemitério Catorze.

Mas tais personagens também circulam por outros espaços abastados, como o apartamento do jornalista PauloPausado e a casa do Ministro - locais de encontros, negociações, articulações, além de festas regadas a bebida e comida fartas. É a partir das andanças de VendedorDeConchas e do Cego na tarefa diária de zungar que o leitor tem acesso à zona da cidade onde o desnível vertical e horizontal se manifestam. Buscando aproximar-se da casa de Pomposa, esposa do Ministro, para oferecer conchas e outros "produtos" do mar, as duas personagens deparam-se com "um largo pacato com casas vastas, casas de muatas, com guardas à porta, algumas com dois e três 
militares, outras com guardas dessas empresas de proteção" (ONDJAKI, 2013, p. 59). Deparam-se, ainda, com chineses habitando em casas confortáveis numa indicação das tensões entre pertença nacional e esse "outro", estrangeiro, gozando do espaço outro/ modernizado da nova Luanda, como analisa Claudia Gastrow (2017a) ${ }^{3}$.

Ao chegar, finalmente, à casa da esposa do Ministro, as personagens da PraiaDallha se deparam com todo o conforto que lhes falta (ONDJAKI, 2013, p. 61):

pela porta viam-se o jardim da casa, a relva cortada com desenhos lindos que o vendedor apreciava por fazerem conjunto com as flores, rosas, cravos, lindas trepadeiras que saíam do jardim e invadiam a varanda, catos, enormes rosas de porcelana e fetos de um verde-escuro que lhe lembrava o mar

- mais-velho, se você ainda pudesse espreitar esse jardim... até dá alegria de uma pessoa olhar

${ }^{3}$ Em decorrência das relações comerciais de Angola com a China, dados apresentados por Claudia Gastrow (2017a) mostram que havia, aproximadamente, 259 mil cidadãos chineses vivendo em Angola em 2012. Esse aspecto aparece tematizado diversas vezes no romance, seja na circulação de produtos diversos, como motocicletas, peças de automóveis; seja na presença da língua e de migrantes chineses, episódio elucidado com mais veemência quando o dono do Bar ArcaDeNoé retira, de seu imóvel alugado, uma família, inicialmente composta por sete chineses, e, um ano depois, com onze. 
- eu estou a sentir o cheiro. tem muitas flores, né?

o olhar do vendedor viajou pelos móveis brilhantes da varanda [...] e, já lá dentro, volumosos cortinados.

o guarda voltou, encostando o portão, cessando a visão

Desse espaço urbano planejado, completamente interditado às duas personagens, surge Pomposa - bem vestida, coberta de ouro dos pés à orelha - e escolhe as maiores e exibíveis conchas, produtos pelos quais paga em dólares, depois de negociar o valor com o vendedor.

Essa estratificação é aprofundada, ao longo da narrativa, à medida que o narrador enquadra os contrastes entre: os que gozam de habitações em bairros planejados (com seguranças que mantêm esses espaços inacessíveis a subcidadãos) e os que se contentam e se sentem gratos pela sorte de terem acesso a apartamentos esvaziados, sem porta nem janelas; os que habitam em musseques; aqueles que improvisam abrigos em subterrâneos ou em restos de automóveis abandonados; por fim, aqueles aos quais sequer a visão de uma morada é permitida. Constrói-se, via literatura, o mapa da urbe, com seus espaços visíveis, superficiais, mas também com suas fendas, suas desigualdades, cuja forma segregada e segrega- 
cionista embrionária situa-se, como argumenta Mahmood Mamdani (1998), no projeto colonial europeu.

Acerca da lógica colonial urbana gestada no projeto da capital angolana, a arquiteta Maria Manuela Afonso da Fonte (2007, p. 148) assim a resume: "num primeiro espaço temos a cidade dos brancos (objeto de processo de urbanização), num segundo espaço a cidade mista [...], e em último lugar a cidade dos negros, com bairros indígenas, juntamente com os musseques, deixados em maior liberdade ou ao acaso". Adiante, a autora prossegue: "os planos [urbanísticos implementados pelos portugueses em Luanda] serviam para criar bairros específicos para as várias raças, para criar estruturas urbanas diferentes para cada uma das expressões sociais e raciais" (2007, p. 156). Embora se tenha mantido a utopia de uma cidade que se democratizaria no pós-independência, a Luanda do século XXI parece assumir cada vez mais uma natureza desigual configurada no seu espaço construído, com novas formas de segregação, materializada em ilhas de fartura e segurança versus espaços fraturados de violência, onde a ausência de políticas estatais (de água encanada, eletricidade, de emprego, de alimento, de educação) é a ordem vigente.

Ao tratar da persistência dessas estruturas ou "detritos coloniais" no presente, a antropóloga norte-americana Ann Laura Stoler (2008) aponta a existên- 
cia de durabilidades menos dramáticas de coerção que as formações imperiais produzem como características contínuas e persistentes de suas antologias, mas que são postas de lado, como se fossem menos urgentes e menos relevantes para as prioridades globais e políticas na atualidade. Tais durabilidades saturam o subsolo da vida das pessoas e persistem, às vezes de maneira subjacente, por um longo período, e continuam a ligar potenciais humanos a ambientes degradados. Stoler contesta a expressão "herança colonial", considerando que ela não consegue captar o espaço evasivo das formações imperiais passadas e presentes, bem como as percepções e práticas pelas quais as pessoas são forçadas a contar com características daquelas formações às quais elas permanecem vívida e imperceptivelmente ligadas. A autora opta, então, por tratar a vida política dos escombros imperiais a partir da noção de ruína, entendida não em seu uso comum nem como espaço encantado visitado por turistas. Mas como uma qualidade duradoura dos restos imperiais e o que eles representam nos estados debilitados. Tais efeitos, conforme Stoler, residem nos buracos corroídos, nas infraestruturas destruídas das paisagens urbanas segregadas e nas microecologias da matéria e da mente. 0 foco, então, não está nos restos inertes, mas na sua refiguração vital. Dentre outras questões, a pesquisadora aponta: como as formações imperiais persistem em seus 
detritos materiais, em paisagens arruinadas e pela ruína social da vida das pessoas?

Em Os transparentes, essas estruturas menos visíveis, essas ruínas, expressam-se a partir da perspectiva de um narrador que parece colher os detritos disseminados pela política econômica imperial e reforçados pelas políticas contemporâneas (MAMDANI, 1998). Tal imagem é construída no romance em tela pela tentativa do Carteiro de chegar a casa, depois de passar o dia rondando a cidade, entregando correspondências:

parou o corpo cansado para mirar com assombro a enorme montanha de lixo que o separava da sua casa, há anos que o trajeto era este [...], o Carteiro entrava no seu musseque, cruzava várias casas, curvava por becos de chão irregular e molhado por águas imundas, e antes de chegar a casa atravessava a enorme montanha de lixo que dividia, na realidade, dois musseques, um riozinho de água escura desenhava no chão curvas que imitavam, com muito boa vontade, um enorme mapa de Angola [...]

respirou fundo interpretando todos os odores, deixou-se invadir por uma estranha tristeza, uma dor que era ao mesmo tempo uma profunda saudade de casa e um medo de nunca chegar até ela 
[...] com as duas mãos sob o queixo pôs-se o homem a olhar a lixeira como nunca tinha olhado, devagar, vagueando pela instalação de restos nos seus contornos inacreditáveis e sua extensão em altura e largura, a diversidade das suas cores, o equilíbrio sujo dos seus odores, as formas que pôde imaginar, ora lhe parecia ver [...] figuras mais ou menos humanas, ou de seres mais ou menos vivos, naquela que era uma espantosa acumulação do que as pessoas deitam fora, ou porque não querem, ou por não ter utilidade, ou por simplesmente cheirar mal

esse amontoado de coisas inúteis e putrefatas impedia fisicamente o Carteiro de chegar a casa (ONDJAKI, 2013, p. 372; p. 374. Grifos nossos)

A imagem suscita outra, criada por Baudelaire ao se referir ao lugar do poeta na moderna Paris do século XIX e retomada por Walter Benjamin em Charles Baudelaire. Um lírico no auge do capitalismo (1991, p. 78): "Aqui temos um homem - ele tem de recolher na capital o lixo do dia que passou. Tudo o que a cidade grande jogou fora, tudo o que ela perdeu, tudo o que desprezou, tudo o que destruiu, é reunido e registrado por ele". Costurando a narrativa entre as diversas camadas da cidade, o narrador-trapeiro da Luanda moderna do século XXI circula por entre casas e becos de chão irregular, projeta, no riozinho-esgoto a (es)correr pelo chão do musseque, a imagem 
do mapa de Angola e, ao acompanhar os passos do entregador de correspondências, contempla e sente, com todos os sentidos e com a imaginação dessa personagem-trapeira, o cenário putrefato da enorme montanha de rejeitos da modernidade a se esparramar como monstro, comprimindo dois musseques e interditando os caminhos ao lar.

Ausente das descrições ou da voz do narrador durante quase todo o romance - embora o Carteiro apareça desde as primeiras páginas -, o musseque/a casa dessa personagem desaparece no instante em que surgiria ao leitor, materializando-se, assim, a "profunda saudade de casa" e "o medo de nunca chegar até ela". Para uma análise mais detida desse ponto do romance e do que ele representa para a compreensão das tensas relações entre pertencimento e exclusão nesta cidade global - onde montanhas de lixo compostas pelo que cidadãos descartam suscitam contornos de (outras) "figuras mais ou menos humanas" e "de seres mais ou menos vivos" -, parecem-nos relevantes as análises desenvolvidas por Claudia Gastrow (2017a, 2017b). A antropóloga avalia as novas estéticas urbanas em Luanda e suas implicações (como o apagamento de construções antigas, mnemônicas, e o surgimento de condomínios fechados que cimentaram as ruínas de assentamentos informais demolidos em nome da nova urbe) como um 
projeto político destinado a curar as feridas da guerra e consolidar a posição do MPLA no poder, exercido literalmente através da transformação da paisagem de Luanda.

A partir de relatos coletados sobre os modos como os moradores da capital do país percebem a estética urbana, a autora argumenta que há uma dissensão estética, isto é, embora muitos tenham expressado admiração pelos projetos de redesenvolvimento urbano, esse ponto de vista é acompanhado por uma forte crítica e, por vezes, por completa rejeição da estética urbana proposta, uma vez que, à medida que os moradores se sentem cultural e economicamente excluídos das políticas de urbanismo da nova cidade, colocam-se em debate, novamente, os conflitos sobre pertencimento nacional e urbano no país. A compreensão dessa perspectiva manifestada pelos moradores passa pelo contexto histórico. Ainda que as ações de guerra tenham se passado, sobretudo, no interior do país, milhões de refugiados, oriundos das províncias onde os palcos do conflito armado se davam, espalharam-se em musseques e outras áreas de Luanda, ocasionando uma crise imobiliária. No período pós-conflito, a reconstrução dessa cidade significou uma nova Lei de Terras, um urbanismo higienista e um imaginário estético que, na prática, implicou: o achatamento e a eliminação de prédios antigos e de 
musseques; o despejo de moradores, considerados agora ocupantes ilegais dessas áreas tidas como atrasadas e desordenadas, dando lugar a novos empreendimentos imobiliários. A ausência em quase toda a narrativa e o aparecimento-desaparecimento da casa e de todo o musseque do Carteiro, tomado primeiro pelo lixo e depois pelo fogo, é representativo da violência da política habitacional adotada pelo governo do MPLA que, tanto em seus fundamentos político-econômicos quanto em seus produtos estéticos, empurrou os angolanos para fora da cidade (GASTROW, 2017a). A cena construída no romance pode ser lida, portanto, como uma dissensão narrativa em relação à política promovida como indicadora de reconstrução nacional e prosperidade, mas marcada, na realidade, pela ausência de perspectivas econômicas e culturais para os mais pobres e pela experiência de deslocamento em consequência do descarte dos mais humildes em zonas distantes, sem nenhuma infraestrutura.

Em perspectiva semelhante à apresentada por Gastrow, os membros do WReC, na análise que fazem da Joanesburgo de Vladislavic, consideram que essa cidade revela seus ritmos centrais por meio de certas chaves contrapontísticas, como a tensão entre memória e esquecimento; entre modos de habitação lícitos e ilícitos; e a tensão entre movimento e estase (2015, p. 153). Guardadas as devidas especifici- 
dades, tais tensões também podem ser lidas em $O s$ transparentes: no passado da cidade que reside-resiste na memória afetiva de Odonato, na referência histórica à lagoa/fonte de água do prédio da Maianga e à cultura e musicalidade do bairro; na resistência dos moradores que ocupam o prédio no coração da Maianga e na bricolagem de materiais empregados na construção de casas nos musseques (regidos por uma lógica vernacular de urbanismo) que perfuram o imaginário estético da cidade planejada.

Sob a superfície da modernidade da cidade com prédios de paredes de vidro espelhado, percorrem as escavações e túneis da cidade esburacada pela CIPEL e pela falta de saneamento, um mundo subterrâneo seccionado pelo encanamento privatizado de água e pelas perfurações de petróleo que avançam sobre buracos onde vagam corpos de meninos sem lar que, contemplados pelo jornalista da janela de seu apartamento com mesa farta, improvisam o sonho de uma morada que indique as suas permanências à cidade:

Paulo viu o fim da noite dos miúdos que cheiravam gasolina, recolhendo os seus corpos para dentro dos seus casebres improvisados em papelão e sacos plásticos, ou em viaturas abandonadas e agora decoradas com arrojo e imaginação para formarem os possíveis lares que os protegem da geada, do mosquito, do vento, da chuva, mas sobretudo lugares que 
imitam a ternura de um lar numa zona escura do céu, tão alta que custava saber da razão matemática dessa distância, uma estrela cadente riscou de luz a noite madrugadora de Paulo e ele por dentro sorriu. (ONDJAKI, 2013, p. 121-122)

De forma sintética, o fragmento esgarça o abismo social e espacial, metaforizado na distância entre o céu e a terra, entre os que possuem a cidade e os que sobrevivem entre ruínas. Se Luanda é local-chave de expressões da modernidade e do desenvolvimento uno e desigual, a obra de Ondjaki pode ser lida como expressão, no campo da cultura, das condições materiais dessa cidade. Como se pode notar nos fragmentos do romance aqui inseridos, a irregularidade espacial é incorporada aos seus aspectos formais. A própria escrita é reorganizada em relação à norma-padrão, como se a língua atuasse também como espaço desestruturado. Não se usam letras maiúsculas, a não ser em nomes de personagens, que nem sempre têm nomes de pessoas. Faz-se justaposição de substantivos comuns e adjetivos para compor nomes próprios. Como um traço da transparência ou da invisibilidade dos sujeitos, algumas personagens atendem apenas pela profissão que desempenham; usa-se vírgula (e às vezes nenhum sinal de pontuação) para encerrar parágrafos. 0 discurso também assume um aspecto 
bastante plástico, modulado entre a sátira, o sarcasmo, a ironia e o humor (na caracterização de atos de personagens ligadas ao poder público) e a linguagem poética (quando se trata de sensações, reflexões e perspectivas ligadas às personagens do prédio da Maianga e dos que a ele se associam).

No nível da narração, o enredo enquadra cenários do desenvolvimento desigual, como se o narrador conduzisse a um mosaico de paisagens urbanas deterioradas, fazendo com que o leitor acompanhe, da janela de um ambiente a outro, as evidências dos estratos da urbe, da segregação social e espacial que caracteriza a realidade do canteiro de obras em que se transforma Luanda na era do capitalismo neoliberal. Em sinal de que a mercantilização das relações sociais violenta até mesmo os vínculos de linguagem, a narrativa situa as diversas tentativas do Carteiro de fazer chegar ao Ministério carta escrita à mão, num papel de 25 linhas, como antigamente. Ao se aproximar de cidadãos (ministros, médico, empresário) que poderiam atuar, junto à administração governamental, como intermediários de sua petição profissional por um veículo motorizado, é tratado como pedinte, um subcidadão marcado nos ombros pelo peso da sacola com comunicações e no rosto com uma bofetada desferida pelo segurança do Ministro, que o leva ao chão. Interditado do sistema comunicativo também 
está o jornalista PauloPausado, impedido de anunciar os fatos sobre o não abastecimento de água e os riscos envolvidos nas escavações da CIPEL.

A estética da desigualdade insere-se também na junção de formas modernas e arcaicas, como os fragmentos da oralidade que abrem cada uma das oito partes do romance e as canções e provérbios pronunciados em umbundo pela AvóKunjikise. Há ainda a junção de elementos do realismo formal (que apreende a cidade dura, cruel, de um realismo selvagem) com elementos do realismo animista, como os efeitos anatômicos de Odonato, cujas paredes insólitas do corpo se assemelham às do prédio. Saudoso de "Loanda", a personagem, vivendo agora numa Luanda sufocante, carrega em si a dupla inscrição do realismo: ao deixar de comer (para dar aos filhos a chance de se alimentarem melhor e, depois, por se recusar a aceitar restos), sua condição transparente e flutuante confere-lhe dignidade e o alça à condição sobrenatural inscrita na cultura tradicional angolana.

Desencobrem-se, assim - pela forma romanesca, pela linguagem, pela narrativa- as camadas arruinadas, os detritos imperiais, e denunciam-se as políticas de uma cidade que assassina e é assassinada. Morrem Ideologia, o Presidente, o jornalista. Morrem o musseque e a casa do Carteiro, tornados cinzas pelo fogo de um petróleo imaginário. Morre CienteDoGrã, 
cujo corpo em vida é abandonado pelo Estado, amontoado com outros em presídios vigiados por policiais que, durante expediente de trabalho, exploram corpos de meninas em prostíbulos e exigem de um pai, transparente de fome, bife e batata frita em troca de falsas informações sobre o filho aprisionado; morrem meninos e jovens, sem acesso à educação, despejados como indigentes no Cemitério Catorze. Morre a cidade, corpo dissecado pelos cipelinos, cujos buracos decorrentes das escavações da busca por petróleo se misturam a outros, decorrentes da falta de saneamento. A Luanda de Ondjaki se transforma, então, numa espécie de necrópole, com seus buracos-catacumbas espalhados por toda a urbe. A promessa de óleo negro é a pólvora que cria a cena apocalíptica com que a narrativa se inicia e termina.

Nascida de um projeto colonial, segregado e segregacionista, fundado na lógica colonizador versus colonizado, a destruição de construções coloniais e as novas edificações no pós-independência não põem fim à exclusão nessa capital neoliberal. Pelo contrário, aprofundam e permanecem criando espaços que reforçam a lógica da exclusão e do não pertencimento. Não obstante vozes críticas, como a do Esquerdista (escritor e poeta), tal qual o velho do Restelo a desconfiar dos projetos de modernização e de futuro - "-é preciso algum cuidado com aquilo que se desig- 
na por progresso" (ONDJAKI, 2013, p. 235) -, o único projeto que ressoa na Luanda cidade-mundo é o da modernidade, una e desigual.

Referências

BENJAMIN, Walter. Charles Baudelaire. Um lírico no auge do capitalismo. 2. ed. São Paulo: Brasiliense, 1991. (Obras Escolhidas III)

CASANOVA, Pascale. A república mundial das letras. Tradução de Marina Appenzeller. São Paulo: Estação Liberdade, 2002.

DAMROSCH, David. What is world literature? Princeton and Oxford: Princeton University Press, 2003.

FONTE, Maria Manuela Afonso da. Urbanismo e arquitectura em Angola - de Norton de Matos à Revolução. 2007. 624f. Tese (doutorado em Planejamento Urbanístico) - Faculdade de Arquitectura, Universidade Técnica de Lisboa (FAUTL), 2007. Disponível em: < https://www.repository.utl.pt/handle/10400.5/2027>. Acesso em: 22 setembro 2019.

GASTROW, Claudia. Aesthetic dissent: urban redevelopment and political belonging in Luanda, Angola. In: Antipode, v. 49, n. 2, p. 377-396, 2017a. Disponível em: <https://onlinelibrary.wiley.com/doi/abs/10.1111/ anti.12276> . Acesso em: 11 março 2019. 
. Cement citizens: housing, demolition and political belonging in Luanda, Angola. In: Citizenship Studies, v. 21, n. 2. p. 224-239, 2017b. Disponível em:<https://www.tandfonline.com/doi/full/10.10 80/13621025.2017.1279795>. Acesso em: 15 abril 2019.

MAMDANI, Mahmood. Ciudadano y súbdito: África contemporánea y el legado del colonialismo tardio. Traducción de Isabel Vericat Nuñez. Mexico: Siglo XXI, 1998.

MBEMBE, Achille; NUTTALL, Sarah. Introduction: Afropolis. In: NUTTALL, Sarah; MBEMBE, Achille (eds.).Johannesburg: The Elusive Metropolis. Durham and London: Duke University Press, 2008.

MONIÉ, Frédéric, AMORIM Vânia; GAYER, Gabriel. A inserção da África Subsaariana no "sistema-mundo": permanências e rupturas. In: EMERSON DOS SANTOS, Renato (org.). Diversidade, espaço e relações étnico-raciais: o negro na geografia no Brasil. Belo Horizonte, Autêntica Editora, 2007. p.175-198.

MONIÉ, Frédéric. Petróleo, desenvolvimento e dinâmicas espaciais na África subsaariana In: MONIÉ, Frédéric, BINSZTOK, Jacob (org.). Geografia e geopolítica do petróleo. Rio de Janeiro: Mauad X, 2012. p. 201-236.

MORETTI, Franco. Conjectures on world literature. In: New Left Review, jan-feb, p. 54-68, 2000. Disponível em: < https://newleftreview.org/issues/II1/ 
articles/franco-moretti-conjectures-on-world-literature>. Acesso em: 21 março 2019.

ONDJAKI. Os transparentes. São Paulo: Companhia das Letras, 2013.

STOLER. Ann Laura. Imperial debris: reflections on ruins and ruination. In: Cultural Anthropology, vol. 23, Issue 2, p. 191-221, 2008. Disponível em: < https://anthrosource.onlinelibrary.wiley.com/doi/abs /10.1111/j.1548-1360.2008.00007.x>. Acesso em: 2 maio 2018.

WALLERSTEIN, Immanuell. Análisis de sistemas-mundo: una introducción. Traducción de Carlos Daniel Schroeder. Mexico: Siglo XXI, 2005.

WARWICK RESEARCH COLLECTIVE (WReC). Combined and Uneven Development: Towards a New Theory of World-Literature. Liverpool: Liverpool University Press, 2015. 